\title{
High Prevalence of First Forced Sex and Determinants of HIV/AIDS among MSM in South India
}

\section{Rakesh Kumar Singh, Santosh Kumar Sharma and Ayantika Biswas}

International Institute for Population Sciences, Mumbai, India

Corresponding author: Santosh Kumar Sharma, International Institute for Population Sciences, Mumbai, India, Tel: 919869941290; Email: santoshiips88@gmail.com

Received date: August 12, 2016; Accepted date: August 26, 2016; Published date: August 31, 2016

Citation: Singh RK, Biswas A, Sharma SK. High prevalence of first forced sex and determinants of HIV/AIDS among MSM in South India, J HIV Retrovirus. 2016, 2:3.

Copyright: (c) 2016 Singh RK, et al. This is an open-access article distributed under the terms of the Creative Commons Attribution License, which permits unrestricted use, distribution, and reproduction in any medium, provided the original author and source are credited.

\section{Abstract}

Background: Forced sex is one of the risk factors of psychological morbidities, HIV and other sexually transmitted infections. Limited studies on MSM are available in Indian context and no systematic attempt has been made to assess the impact of first forced sex on males and as a risk factor of HIV. Therefore, the present study has examined the prevalence of first forced sex as well as its linkage with HIV infection in South India.

Methods: The present study has been used data from the cross sectional survey known as Integrated Behavioural and Biological Assessment during 2009-2010. The survey was conducted in the selected districts of states namely, Andhra Pradesh, Tamil Nadu and Maharashtra. The sample size of MSM was 3875. Bivariate and multivariate logistic regression analysis was used.

Results: Those MSM who have reported of their first forced sex with males, are found more likely to be HIV positive (34.69\% vs. $29.06 \%$ and $O R=1.297, p<0.05$ ) as compared to those MSM who did not have first forced sex with males. In Tamil Nadu, prevalence of first forced sex with males among MSM highest in Salem (57.1\%) followed by Madurai (56.4\%) and Dharmapuri (51.2\%). In Andhra Pradesh, $23.5 \%$ MSM have had first forced sex with males in Hyderabad followed by Guntur (16.8\%), East Godavari (8.8\%) and Vizag (4.0\%).

Conclusion: The present study has found that first forced sexual intercourse with a male is a significant risk factor for the HIV infection among MSM in South India. Therefore, there is an urgent need to control the prevalence of first forced sex and transmission of HIV infection.

Keywords:

HIV; MSM; India; AIDS; Forced sex

\section{Introduction}

Forced sex is one of the risk factors of psychological morbidities, HIV and other sexually transmitted infections (STI) [1-5]. Previous studies have shown that experiencing sexual violence in childhood/adulthood has impacted their health negatively, making them more prone to HIV and even physical and mental disability, for instance, depression [6-9]. Men who have sex with men (MSM) are the most exposed population at a high risk of HIV/AIDS in the world [10-12]. MSM in developing countries like India are at a high risk of HIV/AIDS [12]. In India, the prevalence of HIV infection has decreased since the last decade [10]. However, the prevalence of HIV has increased among MSM in southern states of India [10, 13]. In many countries, MSM are a self-identified sub-population. Similarly, in South India, MSM are divided in a few self-identified categories: 'kothis', 'panthis', double-decker', 'bi-sexual' and 'hijra/ transgender'. Kothis (considered as receptive anal or oral sex) are relatively well-organised and a visible subpopulation of the MSM, while, on the contrary, the panthis are referred to as insertive male partner in South India [14]. Sexual discussion in public is a cultural taboo and is highly stigmatized. Consequently, quantitative data among MSM in India is inadequate $[6,10,14]$. However, India's nodal agency for prevention and control of HIV/AIDS, National AIDS Control Organization (NACO) has estimated HIV prevalence in India to be 7.4\% in 2009 among MSM [15] which was more than the prevalence of HIV/AIDS among female sex workers (4.9\%) [13]. Numerous studies have been carried out on forced sex and its magnitude on women but very few studies are available which have considered forced sex among Men who have sex with men (MSM). There has been no systematic attempt made to know the impact of first forced sex with males and HIV infection [1, $16,17]$. Therefore, the present study has examined the prevalence of first forced sex and its association with HIV infection. 


\section{Materials and Methods}

\section{Data}

The present study has used data from the second series of the cross sectional survey known as Integrated Behavioural and Biological Assessment (IBBA) conducted during the period 2009-2010. The survey was conducted in selected districts of the states of Andhra Pradesh (East Godavari, Hyderabad and Vizag), Tamil Nadu (Dharmapuri, Madurai and Salem) and Maharashtra (Pune and Mumbai/Thane) in India. Time location clustering sampling (TLC) methods have been used to recruit the MSM participants from cruising sites such as parks and local train stations. Firstly, systematic random sampling clusters (i.e., venue/time slots) were chosen by probability proportional to size (PPS). Secondly, from the selected clusters, participants were chosen randomly from among all the eligible participants during the selected time slot [detailed methodology related to survey given here $[18,19]$.

In Andhra Pradesh and Maharashtra, inclusion criteria were self-identified MSM who were at least 18 years of age and have had any type of sex (oral, anal and manual) with another man in exchange for cash/kind in the past month. In Tamil Nadu, similar inclusion criteria were adopted, except that the type of sex was limited (only anal sex) with another man in the last one month [20]. Interviews were conducted by trained field workers in the local language of the districts, using a structured questionnaire that included questions on socio-demographic characteristics, sexual behaviours and program exposure. Interviews were conducted in private locations. Blood and urine samples were collected for HIV/STI diagnosis. No rectal samples were collected. Rapid Plasma Reagin (RPR) test was used to diagnose syphilis, which was confirmed by the Treponema pallidum Haemagglutination Assay (TPHA). Neisseria gonorrhoeae (NG) and Chlamydia trachomatis (CT) infections was diagnosed using APTIMA Combo 2 (AC2) nucleic acid amplification test on urine samples. The study protocol was approved by the Indian Medical Council of Medical Research (ICMR) and Family Health International (FHI 360) Protections of Human Subject Committee. Informed consents were obtained from all the participants, and in case of illiterate participants, the questionnaire was administered in the presence of a witness [18-20].

First sex as forced for men was assessed by the question: Were you forced to have sex during the first sexual encounter with a male? Responses were recorded in the categories ' $\mathrm{No}$ ', 'Yes', 'Do not know' and 'No answer'. The author has included only those participants who responded in yes or no because they were sure about the answer and has excluded do not know or no answer from the analysis. Bivariate analysis and logistic regression analysis have been used to assess the relationships with socio demographic, sexual characteristics and HIV infection among MSM. Logistic regression analysis has been used to assess the significance of first forced sex as a risk factor for HIV infection among MSM. The dependent variable is dichotomous; consequently logistic regression analysis has been used. The whole analysis has been performed in SPSS version 20 (SPSS, IBM).

\section{Results}

\section{Prevalence of first forced sex with male among MSM in South India}

Table 1 illustrates the prevalence of first forced sex among men who have sex with men in selected districts from the states of south India. The present study has found that in Tamil Nadu, $51.5 \%$ MSM have reported having had first forced sex with males, which is followed by the prevalence in Maharashtra (16.3\%) and Andhra Pradesh (13.3\%). Prevalence of first forced sex with male among MSM was found to be the highest in Salem (57.1\%), followed by Madurai (56.4\%), Dharmapuri (51.2\%) and Chennai (41.2\%) respectively. In Maharashtra, the prevalence of MSM having reportedly had first forced sex with male in the district of Pune was found to be $19 \%$ and that in the district of Mumbai was found to be $14.2 \%$. In Andhra Pradesh, $23.5 \%$ of MSM have had first forced sex with males in Hyderabad, followed by Guntur (16.8\%), East Godavari (8.8\%) and Vizag $(4.0 \%)$, respectively.

Table 1 Prevalence of first forced sex of men by MSM in selected states and its districts, South India, 2009-2010.

\begin{tabular}{|l|l|l|l|}
\hline \multirow{2}{*}{ State/Districts } & First Forced Sex & & Sample Size \\
\cline { 2 - 4 } & No & Yes & \\
\hline Andhra Pradesh & 86.7 & 13.3 & 1601 \\
\hline East Godavari & 91.2 & 8.8 & 397 \\
\hline Guntur & 83.2 & 16.8 & 404 \\
\hline Hyderabad & 76.5 & 23.5 & 404 \\
\hline Vizag & 96 & 4 & 398 \\
\hline Maharashtra & 83.7 & 16.3 & 652 \\
\hline Pune & 81 & 19 & 279 \\
\hline Mumbai-Thane & 85.8 & 14.2 & 373 \\
\hline Tamil Nadu & 48.5 & 51.5 & 1620 \\
\hline Chennai & 58.8 & 41.2 & 403 \\
\hline Dharmapuri & 48.5 & 51.5 & 408 \\
\hline Madurai & 43.6 & 56.4 & 406 \\
\hline Salem & 42.9 & 403 \\
\hline Total & 70.2 & 3875 \\
\hline & & 57.8 & \\
\hline & & & 49.8 \\
\hline
\end{tabular}

\section{Prevalence of first forced sex with male among MSM by background characteristics and its determinants}

Table 2 reveals the percentage distribution of first forced sex with male among MSM by background characteristics in south India. The prevalence of HIV-positive males among MSM having reported first forced sex with male was $34.69 \%$ as compared to 29.06\% HIV-positive males among those MSM who did not have first forced sex with male. MSM who self-reportedly identified themselves as Kothis (38.9\%) constitute the highest percentage of those with experience of first forced sex followed by hijra/ 
transgender (29.89\%), double decker (23.87\%), bisexual $(17.73 \%)$ and panthi $(12.88 \%)$, respectively. The present study found that those MSM who belonged to old age groups (35-39 or 40+ years) have reportedly had first forced sex with male. The prevalence of MSM having at least 6-10 years education that had first forced sex with male was found to be $33.88 \%$. About 31\% unemployed MSM have reported first forced sex male whereas $22 \%$ of MSM who are students, $33 \%$ of MSM who are self-employed/business, $23.84 \%$ MSM employed in service and the highest prevalence has been found among those MSM who are working as Massager/pun with $35.39 \%$ of the aforementioned population reportedly having had first forced sex with a male. About 50\% MSM have reported having had first forced sex with male who are living with friend/living at hostels; the prevalence is $44 \%$ for those who are living alone whereas it is relatively lesser among those who are living with family (27.89\%). Approximately 33\% MSM, with male sexual partner, have reportedly had first forced sex with male whereas $31 \%$ MSM, without male sexual partner, have reportedly had first forced sex with male. The study found that $22.14 \%$ MSM, with only female sexual partner, had first forced sex with male whereas around $25 \%$ MSM, having both male and female sexual partner, had first forced sex with male.

Table 2 Percentage distribution of first forced sex with male and Logistic regression analysis (unadjusted and adjusted odds ratio) by their background characteristics among MSM in South India, IBBA, 2009-2010.

\begin{tabular}{|c|c|c|c|c|c|c|c|c|}
\hline \multirow{3}{*}{ Background } & \multirow{2}{*}{\multicolumn{2}{|c|}{$\begin{array}{l}\text { First Forced Sex } \\
\text { with man }\end{array}$}} & \multicolumn{2}{|l|}{ Model 1} & & \multicolumn{2}{|l|}{ Model 2} & \\
\hline & & & \multirow{2}{*}{$\begin{array}{l}\text { Odds } \\
\text { Ratio } \\
(\operatorname{Exp} \beta)\end{array}$} & \multicolumn{2}{|c|}{$\begin{array}{l}\text { Confidence } \\
\text { Interval }\end{array}$} & \multirow{2}{*}{$\begin{array}{l}\text { Odds } \\
\text { Ratio } \\
\\
(\operatorname{Exp} \beta)\end{array}$} & \multicolumn{2}{|c|}{ Confidence Interval } \\
\hline & Yes & $\begin{array}{l}\text { Sample } \\
\text { Size }\end{array}$ & & $\begin{array}{l}\text { Lower } \\
\text { Limit }\end{array}$ & $\begin{array}{l}\text { Upper } \\
\text { Limit }\end{array}$ & & $\begin{array}{l}\text { Lower } \\
\text { Limit }\end{array}$ & Upper Limit \\
\hline \multicolumn{9}{|l|}{ Biological Indicators } \\
\hline \multicolumn{9}{|l|}{ HIVIAIDS infection } \\
\hline $\mathbf{N o}^{\circledR}$ & 29.06 & 3358 & 1 & & & 1 & & \\
\hline Yes & 34.69 & 516 & $1.297^{\star *}$ & 1.066 & 1.58 & $1.229^{*}$ & 0.99 & 1.52 \\
\hline \multicolumn{9}{|l|}{ Chlamydia } \\
\hline No & 29.91 & 3831 & & & & & & \\
\hline Yes & $20.93 £$ & 43 & & & & $\mathrm{~N} / \mathrm{I}$ & & \\
\hline \multicolumn{9}{|l|}{ Gonorrhoea } \\
\hline No & 29.81 & 3868 & & & & & & \\
\hline Yes & $25.00 £$ & 4 & & & & $\mathrm{~N} / \mathrm{I}$ & & \\
\hline \multicolumn{9}{|l|}{ HSV2 } \\
\hline No & 38.29 & 316 & & & & & & \\
\hline Yes & 22.08 & 154 & & & & $\mathrm{~N} / \mathrm{I}$ & & \\
\hline \multicolumn{9}{|l|}{ Self-Identity } \\
\hline Kothi $^{\circledR}$ & 38.9 & 2121 & & & & 1 & & \\
\hline Panthi & 12.88 & 466 & & & & $0.296^{\star \star \star}$ & 0.22 & 0.4 \\
\hline Double Decker & 23.87 & 511 & & & & $0.568^{\star \star \star}$ & 0.45 & 0.72 \\
\hline Bisexual & 17.73 & 688 & & & & $0.408^{* * *}$ & 0.31 & 0.53 \\
\hline Hijra/transgender & 29.89 & 87 & & & & 0.648 & 0.38 & 1.1 \\
\hline \multicolumn{9}{|c|}{ Socio demographic indicators } \\
\hline \multicolumn{3}{|l|}{ Respondents age (Years) } & & & & 1 & & \\
\hline$<20^{\circledR}$ & 25.44 & 228 & & & & 0.925 & 0.65 & 1.32 \\
\hline $20-24$ & 25.76 & 1219 & & & & 0.817 & 0.57 & 1.18 \\
\hline $25-29$ & 25.06 & 1161 & & & & 1.324 & 0.88 & 1.99 \\
\hline $30-34$ & 33.71 & 528 & & & & $1.793^{* * *}$ & 1.16 & 2.77 \\
\hline
\end{tabular}




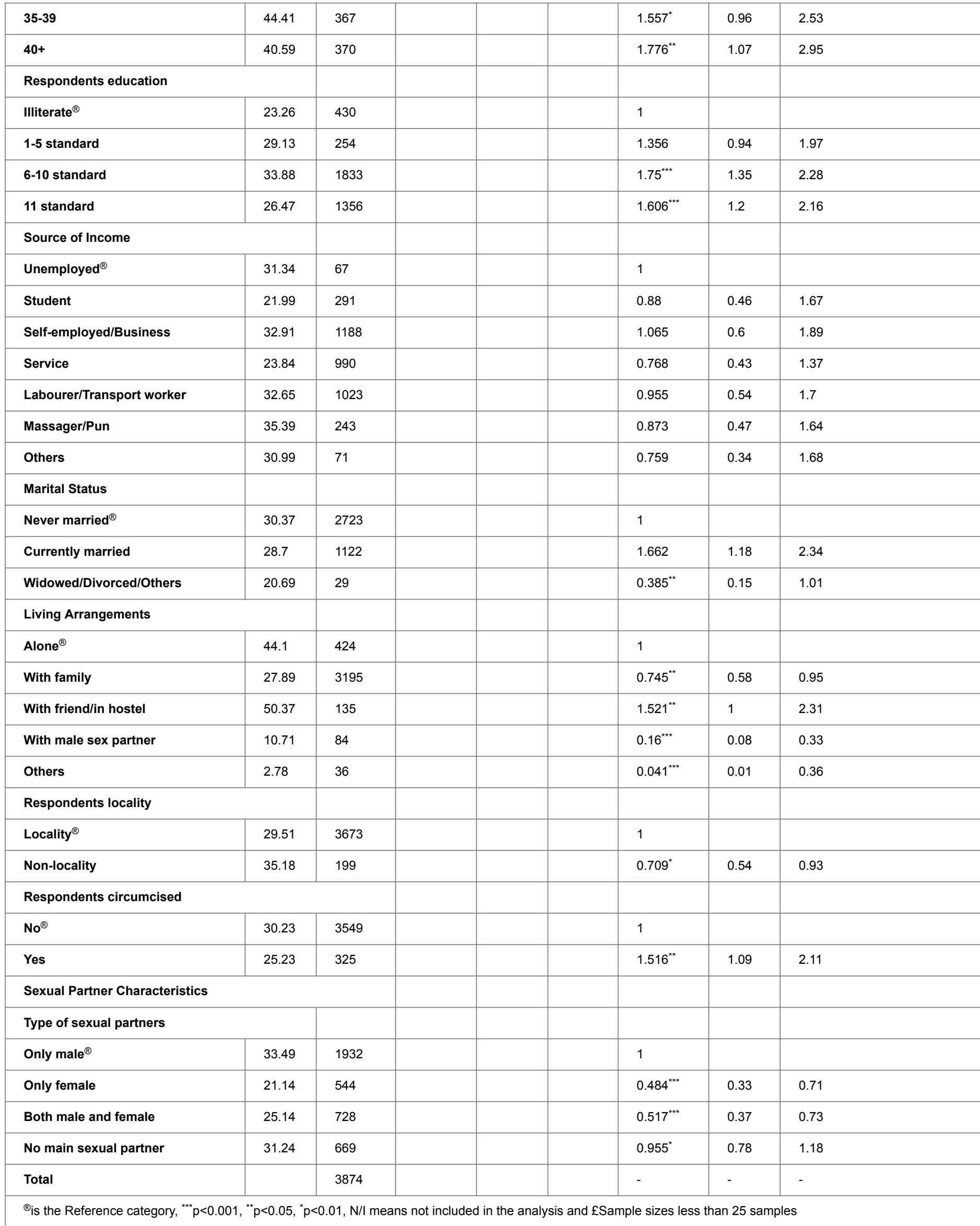


Table 2 also provides information about first forced sex with male as a risk factor of HIV infection. Logistic regression analysis, model 1 provides unadjusted odds ratio whereas model 2 provides adjusted odds ratio by controlling their background characteristics of MSM in south India. In Model 1, MSM with reported first forced sex with male, are found more likely to be HIV-positive (un-adjusted OR=1.297, $p<0.05$ ) compared to those MSM who did not have first forced sex with male. In Model 2, after controlling for demographic, behavioural and sexual characteristics of MSM, it has been found that first forced sex is a risk factor for HIV infection. MSM having had their first sexual encounter as forced were more likely to be HIV infected (Adjusted odds ratio $(A O R)=1.229, p<0.001$ ) as compared to MSM who did not experience their first sexual encounter as forced. MSM living in a hostel or with a friend have been found to be more likely to be HIV-infected (AOR=1.521, $p<0.05)$ as compared to MSM living alone.

\section{Discussion and Conclusion}

To the author's knowledge, this is the first attempt to examine the association of first forced sex with HIV/AIDS among MSM in India. The present study has found a high prevalence of first forced sex (29.8\%) among MSM in southern states of India. The highest prevalence of first forced sex among MSM has been found in Salem (57.1\%), followed by Madurai (56.4\%), Dharmapuri (48.5\%) and Chennai (41.2\%). In addition, the study has found strong evidence of first forced sex as a risk factor for HIV/AIDS among MSM. Furthermore, MSM, who have reported living in hostel or with friends, were more vulnerable to be HIVinfected than MSM, who lived alone. Guadamuz et al. found that men were more likely to have had forced sex owing to their friends that also authenticates the findings of the current study [1].

Studies have shown that forced sex has adverse impact on health, resulting in depression, post-traumatic stress, suicidal ideation [1, 21, 22]. In a study conducted by Stall et al. in 2001, it has been found that children and adolescents who suffered from sexual abuse are more vulnerable to depression and dysthymia, substance abuse disorder, identity disorder and are more prone to HIV and sexual risk behaviours, or to the commitment of sexual criminal offenses [22-25]. Thus, earlier studies have clearly shown the adverse effect of forced sex on health, irrespective of gender.

According to the classification of MSM in South India, some kothis engage in both insertive and receptive sex as doubledeckers. Studies have also shown that most of the kothis are married and involved in sex with both male and female sexual; partners, hence, kothis may be at a high risk of HIV infection and infect both men and women consequently [14, 25]. The present study has found that kothis were more likely to have had first forced sex as compared to the other self-identified subpopulations of MSM. This might be the reason for the high risk of HIV infection among kothis. The study findings revealed first forced sex having been significantly prevalent within the local community among MSM as compared to MSM nonlocalities.
In conclusion, the current study found a significant association of first forced sex with HIV infection among MSM. There is a need for an innovative program that works with MSM, who had first forced sex and provide proper care to combat the depression, substance abuse disorder, sexual risk behaviour and the high prevalence of HIV infection. The present study clearly points out the need for further rigorous research to understand the association of first forced sex on MSM's health and transmission of HIV infection. Future research is required to estimate the prevalence of forced sex and its association with others factors among MSM. This will help to see the impact of violence on the health of MSM.

\section{Limitation of the Study}

Very limited literature is available on first forced sex among MSM in India. Therefore, it is very difficult to compare the findings with previous literature. This would be a limitation of the study. Another issue to consider would be that the results of the study are totally based on a cross-sectional survey, and very limited questions were available in the survey based on first forced sex among MSM in South India.

\section{References}

1. Guadamuz TE, Wimonsate W, Varangrat A (2011) Correlates of forced sex among populations of men who have sex with men in Thailand. Arch Sex Behav 40: 259-266. 
2. Ellickson PL, Collins RL, Bogart LM, Klein DJ, Taylor SL (2005) Scope of HIV risk and co-occurring psychosocial health problems among young adults: Violence, victimization and substance use. Journal of Adolescent Health 36: 401-409.

3. Hoffman S, O'Sullivan LF, Harrison A, Dolezal C, Monroe-Wise A (2006) HIV risk behaviours and the context of sexual coercion in young adults' sexual interactions: Results from a diary study in rural South Africa. Sexually Transmitted Diseases 33:52-58.

4. Lichtenstein B (2005) Domestic violence, sexual ownership and HIV risk in women in the American Deep South. Social Science \& Medicine 60: 701-714.

5. Vlahov D, Wientge D, Moore J, Flynn C, Schuman P, et al. (1998) Violence among women with or at risk for HIV infection. AIDS and Behavior 2: 53-60.

6. Shaw SY, Lorway RR, Deering KN, Avery L, Mohan HL, et al. (2012) Factors associated with sexual violence against men who have sex with men and transgendered individuals in Karnataka, India. PLoS ONE 7: e31705.

7. Shannon K, Kerr T, Strathdee SA, Shoveller J, Montaner JS, et al. (2009) Prevalence and structural correlates of gender based violence among a prospective cohort of female sex workers. BMJ 339: b2939.

8. Dunkle KL, Jewkes RK, Brown HC, Gray GE, McIntryre JA, et al. (2004) Gender-based violence, relationship power and risk of HIV infection in women attending antenatal clinics in South Africa. Lancet 363: 1415-1421.

9. El-Bassel N, Gilbert L, Wu E, Go H, Hill J (2005) HIV and intimate partner violence among methadone-maintained women in New York City. Soc Sci Med 61: 171-183.

10. Ramanathan (2005) Consistent condom use with regular, paying, and casual male partners and associated factors among men who have sex with men in Tamil Nadu, India: findings from an assessment of a large-scale HIV prevention program. BMC Public Health 13: 827.

11. Rhodes T, Simic M, Baros S, Platt L, Zikic B (2008) Police violence and sexual risk among female and transvestite sex workers in Serbia: qualitative study. BMJ 337: a811.

12. Panchanadeswaran S, Johnson SC, Sivaram S, Srikrishnan AK, Latkin C, et al. (2008) Intimate partner violence is as important as client violence in increasing street-based female sex workers' vulnerability to HIV in India. Int J Drug Policy 19: 106-112.

13. (2008) National AIDS Control Organisation (NACO) MoHFW: HIV sentinel surveillance and HIV estimation in India 2007. New Delhi: A Technical Brief.
14. Chakrapani V, Newman PA, Shunmugam M (2008) Secondary HIV prevention among Kothiidentified MSM in Chennai, India, Culture, Health \& Sexuality: An International Journal for Research. Intervention and Care 10: 313-327.

15. (2010) National AIDS Control Organisation (NACO) NACO: Annual report 2009-10. New Delhi: NACO.

16. Holmes WC, Slap GB (1998) Sexual abuse of boys: Definition, prevalence, correlates, sequelae and management. Journal of the American Medical Association 280: 1855-1862.

17. Bartholow BN, Doll LS, Joy D (1994) Emotional, behavioural and HIV risks associated with sexual abuse among adult homosexual and bisexual men. Child Abuse Negl 18: 747-761.

18. Chandrasekaran P, Dallabetta G, Loo V (2008) Evaluation design for large-scale HIV prevention programmes: the case of Avahan, the India AIDS initiative. AIDS 22: S1-S15.

19. Shreena R, Chakrapani V, Ramakrishnan L (2013) Factors associated with use of latex codom-compatible lubricants by men who have sex with men in India: Implications for HIV prevention. Journal of Sexually Transmitted Diseases.

20. Bartholow BN, Doll LS, Joy D, Douglas JM, Bolan G, et al. (1994) Emotional, behavioral and HIV risks associated with sexual abuse among adult homosexual and bisexual men. Child Abuse \& Neglect 18:747-761.

21. Wolfe DA, Francis KJ, Straatman A (2006) Child abuse in religiously-affiliated institutions: Long-term impact on men's mental health. Child Abuse \& Neglect 30: 205-212.

22. Stall R, Millis TC, Williamson J (2003) Association of co-occurring psychosocial health problems and increased vulnerability to HIV/ AIDS among urban men who have sex with men. American Journal of Public Health 93: 939-942.

23. Paul JP, Catania J, Pollack L, Stall R (2001) Understanding childhood sexual abuse as a predictor of sexual risk-taking among men who have sex with men: The urban men's health study. Child Abuse Negl 25: 557-584.

24. Stall R, Purcell DW (2000) Intertwining epidemics: A review of research on substance use among men who have sex with men and its connection to the AIDS epidemic. AIDS Behav 4: 181-192.

25. Verma RK, Collumbien M (2004) Homosexual activity among rural Indian men: Implications for HIV interventions. AIDS 18: 1845-1847. 